\title{
Endoscopic Endonasal Approach for Complex Macroadenoma with Suprasellar and Retrochiasmatic Extension
}

\author{
Edinson Najera ${ }^{1}$ Carl H. Snyderman ${ }^{2} \quad$ Juan C. Fernandez-Miranda ${ }^{1}$ \\ ${ }^{1}$ Department of Neurological Surgery, UPMC Presbyterian, \\ Pittsburgh, Pennsylvania, United States \\ 2 Department of Otolaryngology, University of Pittsburgh, \\ Pittsburgh, Pennsylvania, United States \\ Address for correspondence Juan C. Fernandez-Miranda, MD,
Department of Neurological Surgery, University of Pittsburgh,
200 Lothrop Street, PUH B-400, Pittsburgh, PA 15213, United States
(e-mail: fernandezmirandajc@upmc.edu; tutchkomj@upmc.edu).
}

J Neurol Surg B 2018;79(suppl S3):S284.

\begin{abstract}
In this video, we describe the technical nuances of an endoscopic endonasal approach (EEA) for a complex macroadenoma with suprasellar and retrochiasmatic extension. The patient is a 51-year-old male with several years' history of progressive visual loss. Neuro-ophthalmology assessment revealed a profound visual loss with homonymous hemianopsia and left optic nerve atrophy. His pituitary hormonal profile was normal. The options for surgical approach included transcranial, endoscopic endonasal, or a combination of both. An EEA was the preferred surgical option, because it allows for early identification of the pituitary gland, and provides access to the suprasellar region including pre- and retrochiasmatic spaces, which facilitates tumor removal while minimizing manipulation of the optic apparatus. While most pituitary adenomas do not require extracapsular subarachnoidal dissection, there are complex adenomas with subarachnoidal invasion and multilobulated morphology, such as the one presented here, that require a combination of internal debulking, extracapsular and subarachnoidal dissection. The technique presented here allows for complete tumor resection, avoiding the risk of postoperative apoplexy of residual adenoma, and facilitates identification of perforating branches and neural structures that

\section{Keywords}

- pituitary adenoma

- giant adenoma

- suprasellar extension

- endoscopic endonasal surgery

- surgical anatomy require meticulous preservation. Here, we also illustrate the proper management of reconstruction-related complications. Postoperative course was complicated with meningitis with necrotic nasoseptal flap and required surgical debridement, new inferior turbinate flap, fascia lata, lumbar drain, and 6-week antibiotic treatment. Imaging follow-up showed complete removal of tumor. The patient had significant improvement in visual fields and left visual acuity, and no postoperative hormonal dysfunction. The link to the video can be found at: https://youtu.be/9T5b167bVJA.
\end{abstract}

\section{Conflict of Interest}

None.

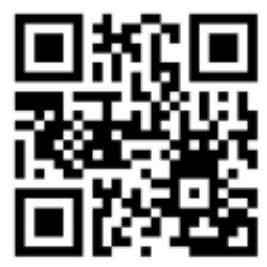

received

October 17, 2017

accepted after revision

December 17, 2017

published online

February 20, 2018

www.thieme.com/skullbasevideos

www.thieme.com/jnlsbvideos

DOI https://doi.org/

10.1055/s-0038-1625969.

ISSN 2193-6331. (c) 2018 Georg Thieme Verlag KG

Stuttgart · New York
License terms

(c) $(1) \$$ 